\title{
MEANINGFUL LEARNING DALAM PEMBELAJARAN MATEMATIKA
}

\author{
D Irmawan ${ }^{1, a}$, D Efendi ${ }^{2, b}, F$ Lestari $^{3, b}$ \\ ${ }^{1}$ Pendidikan Matematika, FKIP, STKIP PGRI Bandar Lampung \\ ${ }^{2,3}$ Prodi Pendidikan Matematika, FKIP, Universitas Muhammadiyah Lampung \\ airmawandiki@stkippgribdl.ac.id, bdenie04@gmail.com, \\ ‘fitria.lestariavicena@gmail.com
}

\begin{abstract}
In the learning process not every student succeeds through the learning process done in other words not every student can achieve the learning objectives as expected. This is due to abstract mathematical concepts. Many factors influence it, including intelligence, learning readiness, interests, motivation, teacher abilities, maturity, family, school and community. The purpose of this study is to know the meaningful influence of learning on students' math learning outcomes. This research uses descriptive quantitative methods. The population in this study is all grade VII students of SMPN 1 Katibung Lampung Selatan. The results of the hypothesis test using the t-test showed the influence of meaningful learning application on improving the results of mathematics learning students of grade VII SMPN 1 Katibung south lampung. Students who apply meaningful learning have a higher average math learning outcome than the average student learning outcomes that do not apply meaningful learning. Thus, the application of meaningful learning can improve students' math learning outcomes.
\end{abstract}

Keywords: Meaningful learning, Descriptive quantitative, Learning outcomes

\section{PENDAHULUAN}

Belajar merupakan usaha yang harus dilakukan sebagai upaya untuk memperoleh perubahan tingkah laku yang lebih baik yang dapat diperoleh melalui hasil pengalaman interaksi individu dengan lingkungan [1]. Selain daripada itu, [2] menyatakan bahwa belajar adalah proses peralihan tanggapan atau reaksi individu terhadap lingkungan sebagai hasil dari pengalaman. Kemudian, [2] mengungkapkan bahwa belajar adalah keadaan perbaikan kemampuan dari runtutan peristiwa dalam perkembangan. 
Matematika diberikan pada tiap tingkat pendidikan. Matematika diharapkan mampu mengasah pola pikir baik dalam kehidupan seharihari maupun untuk ilmu pengetahuan lain. Pembelajaran matematika tidak hanya menuntut siswa untuk sekedar memahami topik yang dipelajari, tetapi juga belajar dengan pemahaman dan secara aktif membangun pengetahuan dari pengalaman dan pengetahuan sebelumnya [3] Akan tetapi, pembelajaran yang optimal terpengaruh oleh kecakapan guru menjadikan kondisi belajar yang kreatif sehingga siswa secara sungguh-sungguh dan terus-menerus dalam mengikuti pembelajaran hingga memproleh hasil yang optimal. Pembelajaran akan lebih baik apabila didukung dengan strategi dan metode yang tepat. Tingkat keefektifan pembelajaran dipengaruhi oleh seberapa baik metode pembelajaran yang digunakan [4] Pembelajaran matematika di sekolah umumnya berorientasi pada target penguasaan materi. Pembelajaran yang menitikberatkan terhadap pemahaman materi telah dapat dibuktikan tercapai dalam kompetensi mengingat jangka pendek, akan tetapi tidak tercapai memberi bekal dalam mengatasi persoalan jangka panjang. Oleh karena itu, pemilihan strategi pembelajaran harus diperhatikan, sehingga siswa dapat dengan mudah memahami dan menerima materi yang disampaikan oleh guru. Salah satu pemilihan strategi tersebut yaitu dengan cara belajar bermakna (Meaningful Learning).

Meaningful Learning adalah rangkaian tindakan mengaitkan informasi baru terhadap konsep-konsep yang relevan [2]. Menurut Ausubel dalam [5] proses Meaningful Learning terjadi jika seseorang mampu melakukan penyesuaian kepemilikan pengetahuan dengan pengetahuan baru. Terdapat tahapan dalam Meaningful Learning yaitu, memperhatikan stimulus; memahami makna stimulus; menyimpan dan menggunakan informasi yang sudah dipahami.

[6] menjelaskan tentang syarat Meaningful Learning yaitu: 1) pengetahuan yang dipelajari memiliki kebermaknaan potensial. Kebermaknaan potensial bergantung pada kebermaknaan logis pengetahuan itu (ajek dan substantif); 2) Pembelajar mempunyai ide yang relevan terhadap pengetahuan yang akan dipelajari; 3) 
Pembelajar mempunyai keinginan untuk mengaitkan ide dengan struktur kognitif yang telah dimiliki. Adapun kelebihan Meaningful Learning menurut [6] antara lain: 1) pengetahuan baru (informasi) lebih lama dingat; 2) menjadika belajar lebih mudah untuk pengetahuan yang sama; 3) pengetahuan yang tidak teringat, menyisakan pengaruh dalam struktur kognitif sehingga dapat dilakukan pemanggilan kembali.

Tahapan Meaningful Learning menurut [5] adalah menetapkan arah belajar, mengidentifikasi siswa dalam hal ini yaitu kecakapan; motivasi; dan gaya belajar, menentukan bahan belajar yang selaras dengan karakteristik siswa kemudian disusun ke dalam konsep inti, memilih topik yang berpenampilan Advance Organizer yang akan dipelajari siswa, mempelajari konsep inti dan diterapkan ke bentuk nyata, serta melakukan penilaian pembelajaran.

\section{METODE PENELITIAN}

Berdasarkan pada masalah yaitu terdapat siswa yang belum paham terhadap materi yang telah diberikan oleh guru mengakibatkan minat siswa terhadap pelajaran matematika rendah juga pembelajaran matematika yang masih berorientasi pada pemahaman materi, peneliti menerapkan Meaningful Learning untuk meningkatkan minat dan hasil belajar matematika siswa terhadap populasi penelitian dalam hal ini juga berperan sebagai subjek penelitian yaitu siswa kelas VII semester genap SMP Negeri I Katibung Lampung Selatan yang terdiri dari dua kelas, kelas VII F sebagai kelas kontrol yang tidak menerapkan Meaningful Learning dan kelas VII B sebagai kelas eksperimen dengan menerapkan Meaningful Learning.

Penelitian ini bertujuan untuk melihat pengaruh Meaningful Learning dalam pembelajaran Matematika. Metode yang digunakan dalam penelitian ini adalah metode kuantitatif. Teknik pengambilan sampel menggunakan teknik Claster Random Sampling, yang terdiri dari 2 kelas yaitu, kelas Eksperimen (kelas yang menerapkan 


\section{Hipotenusa}

Journal of Research Mathematics Education VOL. 4 NO.2 2021

Meaningful Learning) dan kelas Kontrol (kelas yang tidak menerapkan Meaningful Learning). Teknik Pengumpulan data yang digunakan yaitu studi pustaka, observasi, dokumentasi dan tes essai. Uji reliabilitas instrumen menggunakan Indeks Reliabilitas Alat Ukur menurut [7]. Kemudian, validitas dilihat dari logical validity dengan cara validitas kontruksi yaitu dengan merinci dan memasangkan setiap butir soal dengan setiap aspek dalam kompetensi dasar atau dengan kata lain mengukur setiap aspek berpikir. Analisis data dilakukan dengan uji normalitas data dan uji homogenitas varian. Kemudian, uji hipotesis menggunakan uji kesamaan dua rata-rata dan uji perbedaan dua ratarata.
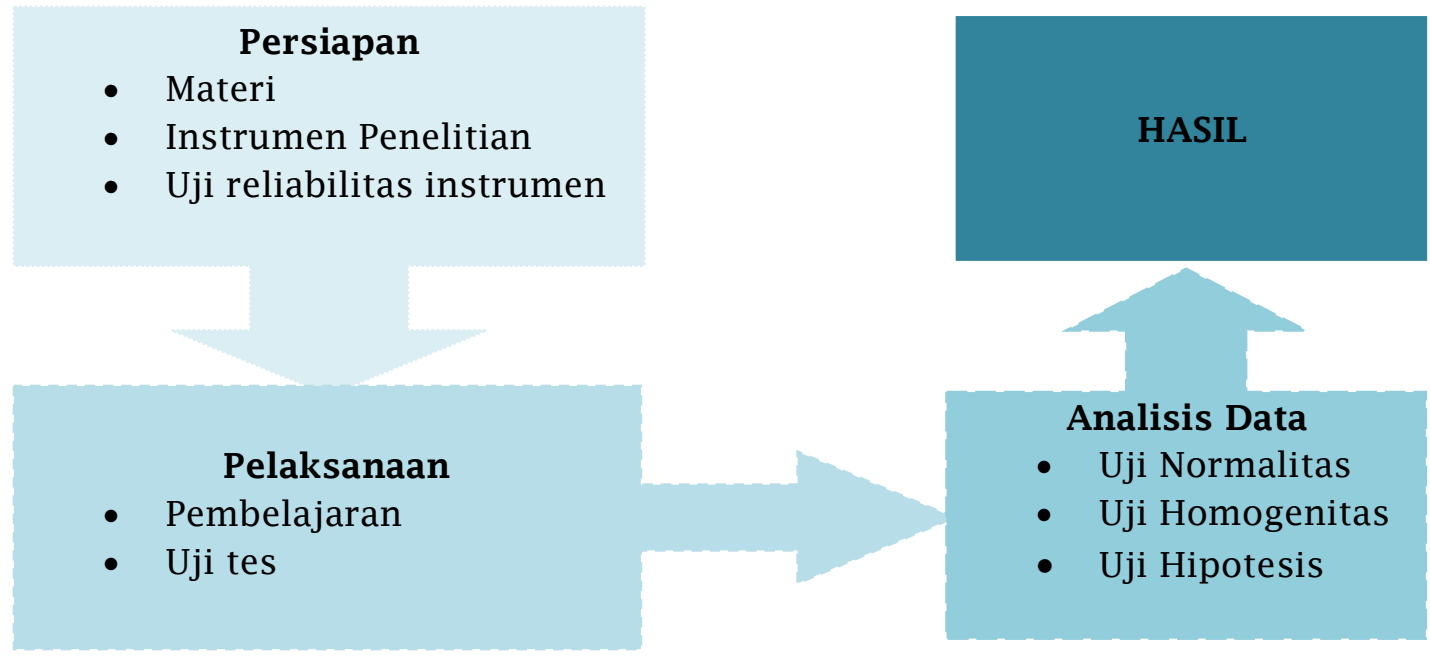

Gambar 1 Tahap Penelitian 


\section{HASIL DAN PEMBAHASAN}

Berdasarkan hasil penelitian, diperoleh nilai rata-rata siswa yang dapat dilihat pada tabel berikut ini:

Tabel 1. Data Hasil Belajar Siswa

\begin{tabular}{cccc}
\hline & & \multicolumn{2}{c}{ Tabel 1. Data Hasil Belajar Siswa } \\
\cline { 3 - 4 } No Nilai & & $\begin{array}{c}\text { Meaningful } \\
\text { Learning }\end{array}$ & $\begin{array}{c}\text { Tanpa } \\
\text { Meaningful } \\
\text { Learning }\end{array}$ \\
\hline 1 & 2 Siswa & 0 Siswa \\
2 & $<78$ & $(20 \%)$ & $(0 \%)$ \\
& & 32 Siswa & 40 Siswa \\
& & $(80 \%)$ & $(100 \%)$
\end{tabular}

Sumber: Pengelola Data

Berdasarkan hasil penelitian tersebut, hasil belajar siswa yang menggunakan Meaningful Learning yaitu, dari 40 siswa diperoleh 20\% siswa yang mencapai nilai $\geq 78$. Sedangkan, hasil belajar siswa yang tidak menggunakan Meaningful Learning yaitu, dari 40 siswa diperoleh $0 \%$ siswa yang mencapai nilai $\geq 78$.

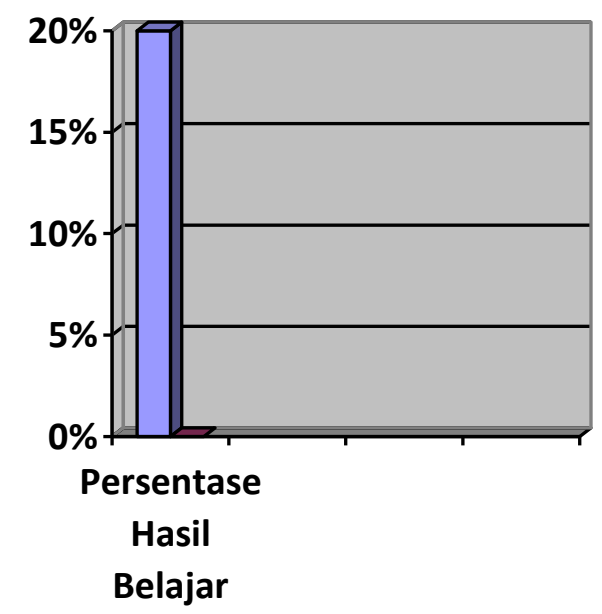

$\square$ Meaningful Learning
$\square$ Tanpa Meaningful
Learning

Gambar 2 Diagram Hasil Belajar 
Hasil belajar matematika siswa dengan penerapan Meaningful Learning lebih tinggi dari hasil belajar matematika siswa tanpa menerapkan Meaningful Learning. Sehingga, terdapat pengaruh terhadap hasil belajar dengan penerapan Meaningful Learning dalam meningkatkan hasil belajar matematika siswa kelas VII SMP Negeri 1 Katibung Lampung Selatan.

\section{KESIMPULAN DAN SARAN}

Berdasarkan hasil dan pembahasan, peneliti menyimpulkan bahwa Meaningful Learning dalam pembelajaran matematika berpengaruh terhadap hasil belajar Matematika siswa. Berdasarkan hasil tes yang diberikan, maka:

1. terdapat pengaruh terhadap penerapan Meaningful Learning dalam peningkatan pembelajaran matematika siswa;

2. angka rata-rata hasil belajar siswa yang menerapkan Meaningful Learning lebih tinggi dari pada yang tidak menerapkan Meaningful Learning.

Berdasarkan kesimpulan yang dijelaskan diatas agar dapat meningkatkan pembelajaran dan kualitas pendidikan terutama pembelajaran matematika, peneliti memberikan saran sebagai berikut:

1. penerapan Meaningful Learning merupakan salah satu sokongan terhadap strategi pembelajaran agar lebih baik lagi yang tak luput dari motivasi oleh guru terhadap siswa sebagai upaya agar siswa merasa senang dalam pembelajaran matematika;

2. menanamkan konsep matematika terkait dengan kehidupan siswa selaras dengan perkembangan kehidupan siswa akan mudah diterima dan bermakna bagi siswa.

Demikian penjabaran dari peneliti berdasarkan pada hasil dan pembahasan penelitian yang telah terlaksana di SMPN 1 Katibung Lampung Selatan. Besar harapan peneliti agar hasil penelitian ini dapat menjadi rujukan oleh para peneliti lain dalam peningkatan taraf pendidikan khususnya pendidikan matematika. 


\section{DAFTAR PUSTAKA}

[1] Slameto, Belajar dan Fakor-Faktor yang Memengaruhinya. Jakarta: Rineka Cipta, 2003.

[2] dkk. Panen, Belajar dan Pembelajaran 1. Jakarta: Universitas Terbuka, 2002.

[3] Munifah et al., "Management Development of Student Worksheets to Improve Teacher Communication Skills: A Case Study Self-Efficacy and Student Achievement," Educ. J. Gift. Young Sci., vol. 7(4), pp. 777-798, 2019, doi: https://doi.org/10.17478/jegys.625618.

[4] F. Lestari et al., "Cooperative Learning Application with the Method of Network Tree Concept Map: Based on Japanese Learning System Approach," Educ. J. Gift. Young Sci., vol. 7(1), pp. 15-32, 2019, doi: https://doi.org/10.17478/jegys.471466.

[5] A. Budianingsih, Belajar dan Pembelajaran. Jakarta: Rineka Cipta, 2005.

[6] J. Sutrisno, Strategi Belajar Mengajar Matematika. Bandar Lampung, 2006.

[7] S. Arikunto, Prosedur Penelitian. Jakarta: Rineka Cipta, 2002. 